\title{
Ozone therapy in dentistry: clinical experiences
}

\author{
Piermarco Babando \\ Periodontology Coordinator, Mauriziano Umberto I Hospital, Turin, Italy
}

\begin{abstract}
The aim of the paper is to investigate in depth how the entry of ozone gas into clinical dental practice can modify common procedures by involving both equipment and clinical procedures. After a careful bibliographic review, clinical proposals for surgical, implant and periodontal treatment are described.
\end{abstract}

\section{Introduction}

Ozone therapy has been used since the 19th century. The first mention of ozone was made by German physicists Martin Van Marun in 1785, but it was Cristian Frederic Schonbein Professor at the University of Basel, who, in 1840, demonstrated changes in the properties of the oxygen molecule with the formation of a particular gas called ozone.

Since the mid 19th century, Dr. Charles Kenworthy has documented his interest in the use of ozone in the medical field, in particular in 1885, he published the book Ozone in Florida where he described in detail the use of ozone in the medical field.

In 1950 Dr. E.A. Fisch in Germany began to use ozonized water in the dental field and in 1959 a machine called Ozonosan was patented by Dr. Joachim Hansler, founding the basis for the expansion of the use of ozone therapy in Germany.

Finally, in 1971 the International Institute of Ozone was founded.

In Italy there is a scientific ozone-therapy society that was founded in 1984 by Prof. Franzini in Bergamo. Since the end of 1992, the Ministry of Health has allowed the experimentation of

\footnotetext{
Correspondence: Piermarco Babando, Scientific Society of Oxygen Ozone Therapy, via Roma 69, 24020 Gorle (BG), Italy.

E-mail: info@ossigenoozono.it
}

Key words: Oxygen-ozone therapy; Dentistry; Clinics.

Received for publication: 5 September 2017.

Accepted for publication: 20 September 2017.

CC Copyright P. Babando, 2017

Licensee PAGEPress, Italy

Ozone Therapy $2017 ; 2: 7083$

doi:10.4081/ozone.2017.7083

This article is distributed under the terms of the Creative Commons Attribution Noncommercial License (by-nc 4.0) which permits any noncommercial use, distribution, and reproduction in any medium, provided the original author(s) and source are credited. therapeutic methods of ozone in the University and Hospital Clinics, which has allowed the standardization of therapeutic protocols.

\section{Peculiar effects of ozone}

Ozone is an allotropic molecule of the chemical oxygen element; it is an unstable gas known since ancient times for the typical smell scattered in the air during thunderstorms (it is not a coincidence that it comes from Greek ozein, i.e. send smell). Ozone is a natural component of the atmosphere and is found in different concentrations in its layers and plays a role in the ecological balance of the earth as it absorbs ultraviolet radiations.

Ozone molecules consist of three oxygen atoms that are produced by subjecting oxygen molecules to the action of electric discharges.

Ozone gas has a high oxidation potential and is 1.5 times higher than hydrochloride, so it is used as an antimicrobial agent.

In the dental field, in particular, the use of ozone has been proposed for its antimicrobial, disinfectant and biocompatibility actions. However, its use has been limited by possible side effects.

Ozone is used as an oxygen/zone mixture in the medical field and does not cause any significant side effects if applied correctly and does not cause allergic reactions of any kind.

At appropriate doses (1-40 $\mu \mathrm{g} / \mathrm{mL}$ of oxygen) ozone does not induce undesirable effects, as there are mechanisms of protection against oxidation intrinsic to the body.

Ozone therapy has become an element of infection therapy in many fields such as surgery, dermatology, and dentistry. The ozone concentrations used may vary between 1 and $60 \mathrm{gm} / \mathrm{mL}$ $(0.05-5 \%)$ according to medical/odontological indications given by the conditions of the individual patient. Controlled ozone applications were found to be safe and without side effects compared to other dressings including antibiotics. It also stimulates blood circulation and immune responses. Bactericidal, virucidal and antifungal activity has been known and expressed for years in industry and medicine. It has been shown to be a potent antimicrobial agent against bacteria, viruses, protozoa fungi and protozoa. The cooperation of European Ozone Societies has shown the precautionary principle of avoiding direct injections of ozone/oxygen gas to avoid the risk of embolism. There are four basic ways of using ozone applicable in the dental field: gas, ozonized water, ozonized oil, ozonized air.

Ozone has mainly the effects explained in what follows.

\section{Antimicrobial action}

Ozone is able to kill all bacteria both gram positive and gram negative including Pseudomonas aeruginosa and Escherichia coli.

The mechanism of action is the ozonolysis of the cytoplasmic membrane combined with secondary oxidizing effects. These actions are non-specific and selective for microbial cells, while 
not damaging human body cells due to their antioxidant properties.

The bactericidal and fungicide action originates from the direct contact between ozone and microorganisms and is due to the destruction of the capsule subjected to the oxidative process caused by the gas and/or peroxides, so DNA and RNA can be attacked.

The attack of the capsule and the subsequent bacterial destruction is made possible for two fundamental reasons: first, because it is rich in lipoproteic components, a characteristic that guarantees its affinity; second, because the bacterial cell possesses scarce defensive mechanisms, for which it remains victim of the oxidizing capacity of the ozone.

If we add to this that there are, however, bacteria that prefer a predominantly anaerobic mechanism, it is easy to understand how ozone in these cases can play a fundamental role in the therapeutic protocol.

Ozone is very effective on resistant antibiotic bacteria and its antimicrobial activity is increased in environment with acid $\mathrm{PH}$.

While the bactericide and fungicide action of ozone has been known for almost a century and continues to find more and more confirmation, the virostatic action is studied and confirmed by some research carried out with particular intensity for about twenty years.

The virostatic action is carried out through two mechanisms of action that probably take place at the same time: i) inactivation of the virus by the action of peroxides; and ii) intolerance of peroxides in infected cells.

Ozone in these conditions is therefore not virucidal but virostatic, it does not kill viruses but inactivates them.

\section{Immunostimulant effect}

Ozone affects the immune system, both cellular and humoral. It stimulates the production of immunocompetent cells and the synthesis of immunoglobulins also activates macrophages and increases the sensitivity of microorganisms to phagocytosis. This gas, both in vivo and in vitro, produces a hematically verifiable immunomodulant effect, with the gradual reduction of serum immunoglobulins and the rapid loss of clearance of circulating immune complexes.

\section{Anti-inflammatory and analgesic action}

These effects seem to be due to several factors: it decreases the production of inflammation mediators; oxidation and therefore inactivation of pain mediators; it increases the local level of blood microcirculation with an increase in oxygen release at tissue level and therefore promotes the elimination of toxins and more generally the resolution of physiological disorders that generate pain.

There are various mechanisms of ozone that determine its antiinflammatory action.

First among them is the activation of monoamine oxidase (MAOs) and diamine oxidase (DAOs), enzymes that actively intervene in the catabolism of histamine. It follows that in the inflammatory outbreak concentrations of this mediator are significantly reduced.

All this results in a decrease in symptoms and signs related to its liberation such as: capillary dilatation, increased capillary permeability, increased contraction of smooth muscles, increased lymphatic flow.

Serotonin, which is decarboxylated by the MAO through ozone, has the same fate and leads to a reduction in signs of its liberation such as pain and increased vasal permeability. There is also an ozone effect on prostaglandins, the synthesis of which is greatly reduced, and it follows that concentrations in the inflammatory outbreak decrease with consequent reduction of symptoms and signs related to their production. The inflamed areas have negative charge (acid), the ozone has positive charge (basic), so it is attracted into the inflammation areas. Endorphin form on site, therefore, has a longlasting antalgic effect in both somatic and neuropathic pain.

\section{Anti-hypoxia action}

The effects of ozone on oxygen metabolism can be explained by its promoting actions of: changes in the theological properties of blood; increased glycolysis velocity of erythrocyte.

Ozone causes an increase in $\mathrm{PO}_{2}$ in tissues and increases the transport of oxygen in the blood; this leads to a change in the activation of aerobic processes of cellular metabolism (glycolysis, Krebs cycle, beta oxidation of fatty acids) and the use of energy resources.

Ozone acts as a super-oxidant, bringing oxygen to tissues and assisting the body in normal healing processes.

In summary, ozone therapy may induce the following biological responses (more frequent within a range of $20-40 \mu \mathrm{g} / \mathrm{mL}$ of ozone per $\mathrm{mL}$ of blood): i) increases the blood oxygen circulation in ischemic tissues due to NO; ii) stimulates metabolism in general by increasing oxygen release; iii) regulates antioxidant enzymes; iv) induces an average activation of the immune system and promotes growth release.

\section{Importance of ozone in dentistry}

Bacteria are the cause of most dental problems and therefore powerful antibacterial agents are needed to eliminate them. Ozone is used as a disinfectant both for its synergistic action on most treatments and because it is able to eliminate bacteria autonomously.

\section{Use of ozone in dental practice}

Ozone is widely used in dental practice. The use of this gas can in fact revolutionize the daily dental practice by involving both the treatment of ambient air and water used. This allows the disinfection and sterilization procedures of both the environments and surfaces and the instruments used to be optimized.

\section{Air treatment}

Ozone has great oxidizing power. It sanitizes and deodorizes environments without the use of chemicals and without leaving any residue. It is a gas and penetrates everywhere. If produced in appropriate quantities it can guarantee environmental saturation allowing environmental sanitization. Saturating the studio environment with ozone can reduce environmental odors and eliminate that classic dental perfume.

The ozone-saturated environment also allows the decontamination of surfaces exposed to gas and the reduction of bacterial load in ambient air. During dental sessions, dental unit water is spread by nebulization together with oral fluids, contaminating the surfaces even at a considerable distance from the dental unit itself. All surfaces exposed to ozone gas crashes are thoroughly decontaminated, allowing bacteria and viruses to be inactivated. The diffusion of gas into the environment must be carried out by falling because ozone is heavier than ambient air.

By completely saturating the environment of the dental practice, it is also possible to sanitize the filters and ducts of the air conditioning/heating apparatus (Figure 1). 


\section{Water treatment}

The use of hyper-ozonated water finds multiple applications in daily dental practice and covers different fields. In fact, it is possible to improve environmental disinfection by hyperozonizing the water used for washing both floors and surfaces, improving decontamination and reducing the use of normal detergents. Bactericidal action of ozone and 300 times greater than that of chlorine (Figure 2).

\section{Use of hyper-ozonated water in the dental patient chair}

If the dental chair is equipped with a mains independent hydraulic circuit, it is possible to hyperozonize the dental unit water before use and with great ease to decontaminate the dental unit. The dental chair is in fact equipped with very small hydraulic circuits in which the stagnation of liquids is encouraged. The sup-

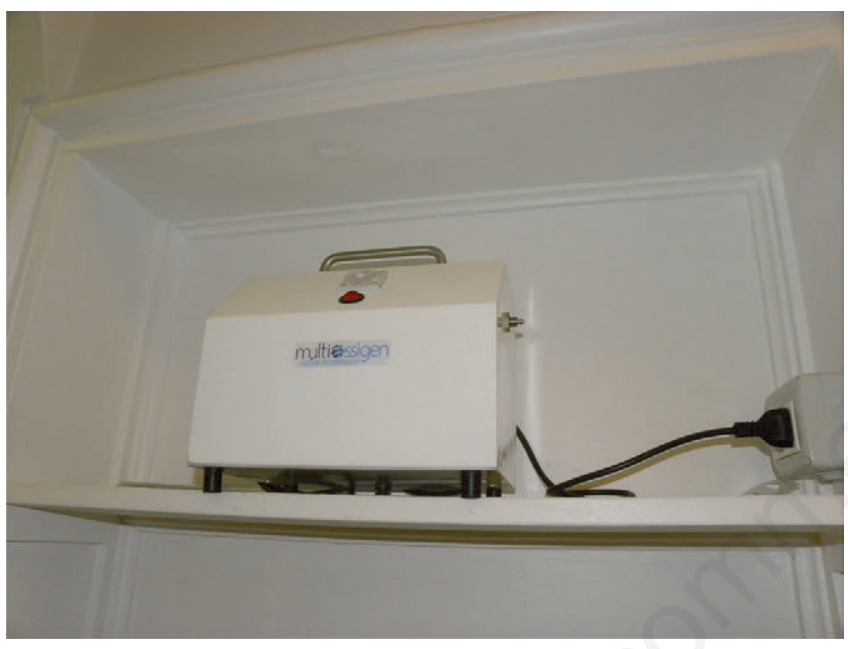

Figure 1. Picture of gas machine Air King Multiossigen [Multiossigen, Gorle (BG), Italy].

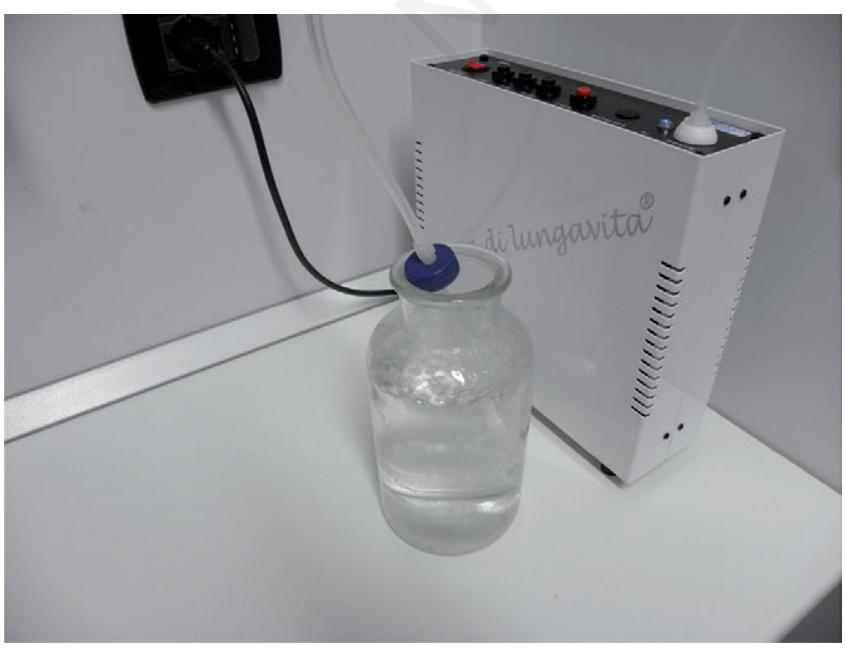

Figure 2. Picture of OM3 Multiossigen [Multiossigen, Gorle (BG), Italy]. ply from the water supply network also allows the flow of microorganisms that proliferate easily inside the same ducts.

Dental units are frequent, which are positive for legionella and other bacterial colonies. The use of hyper-ozonated water allows the use of highly decontaminated water with powerful bactericidal effects that prevent the proliferation of pathogenic microorganisms within the dental unit itself. Hyper-ozonated water also avoids scale problems, improving the functionality of handpieces, scalers and air/water syringes.

Hyper-ozonated water, thanks to its great disinfectant power, not only allows the use of a liquid free of virus and fungus bacteria, but also allows the destruction of the bacterial biofilm that forms inside the pipes and handpieces (Figure 3 ). ${ }^{1}$

\section{Instrumental disinfection}

By immersing surgical instruments in hyper-ozonated water, it is possible to obtain a more effective cleansing of the instruments by facilitating the removal of organic residues and reducing residual bacterial load. ${ }^{2}$ Hyper-ozonated water can also be used inside the ultrasonic washing machine, saving on detergents normally used (Figure 4).

\section{Ozone in my dental practice}

\section{Patient preparation}

The patient who has to undergo any oral surgical procedure involving bleeding, beforehand must rinse with hyper-ozonated water (level high multioxygen OM3) for two minutes (Figure 5). ${ }^{3}$

\section{Preparation of the surgical field}

During surgery, various cooling and intraoperative washing solutions are used. The use of sterile solution of double-distilled water and hyper-ozonated physiological solution (level high multioxygen OM3) make the cleansing and disinfectant action of these solutions much more effective. Using hyper-ozonated solutions to cool surgical handpieces, piezo-electric and ablator handpieces, a more effective debridement of the bacterial biofilm ${ }^{1}$ is achieved

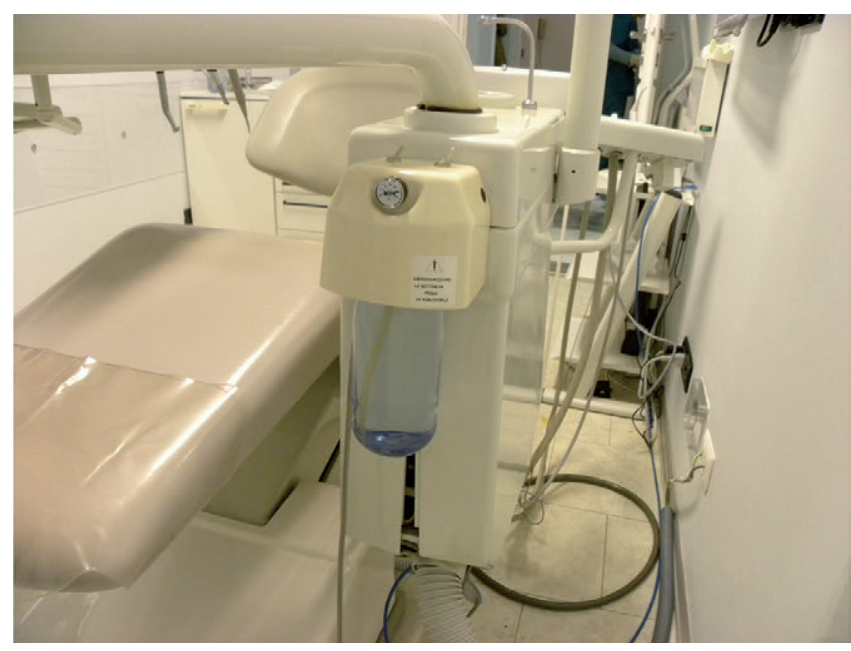

Figure 3. Picture of the autonomous water system on the dental unit. 
with a sharp reduction in the bacterial load of the surgical site. ${ }^{3}$ In addition, there is a significant improvement in patient compliance and a much faster healing (Figure 6).

\section{Ozone inoculation in pre-operative surgical site}

After having performed the regional or local anaesthesia, it is possible to infiltrate the surgical site in order to decrease the bacterial load of the area and obtain a mild hemostatic effect (Figure 7).

\section{Ozone inoculation in post-operative surgical site}

Once the oral surgery has been completed, the surgical wound is covered with ozonized paste [Ozodent Multiossigen, Gorle (BG), Italy] in order to avoid overinfection of the surgical site in the first moments after surgery. The ozonized paste will also have the task of increasing the seal of the surgical wound. In fact, underneath the surgical flap an ozone insufflation is carried out with a high concentration of ozone in order to sterilize the post-operative surgical site. In order to increase the repair processes and increase the blood flow in the coagulum area, the whole area surrounding the surgery will be infiltrated with low concentration ozone (Figure 8).

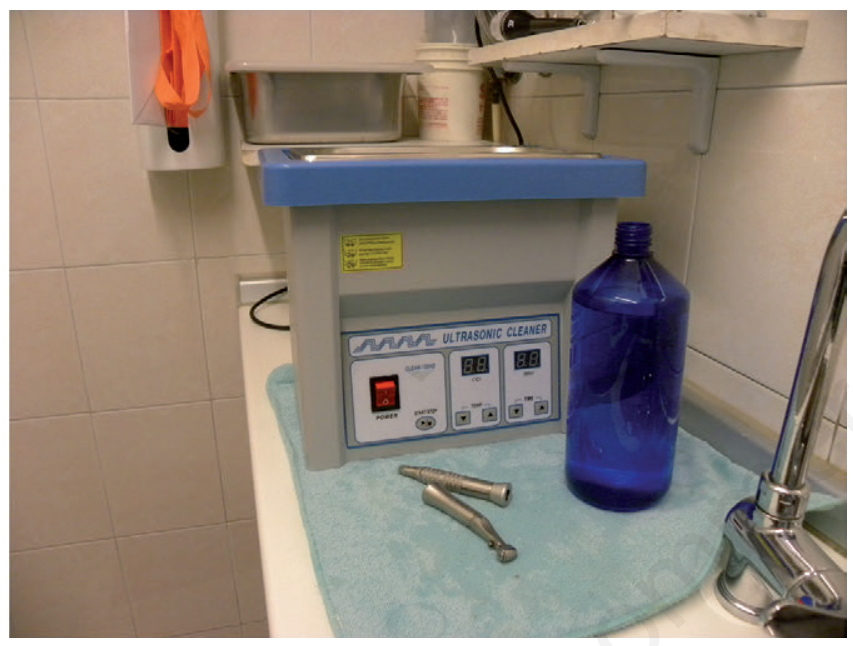

Figure 4. Picture of ultrasonic washing machine.

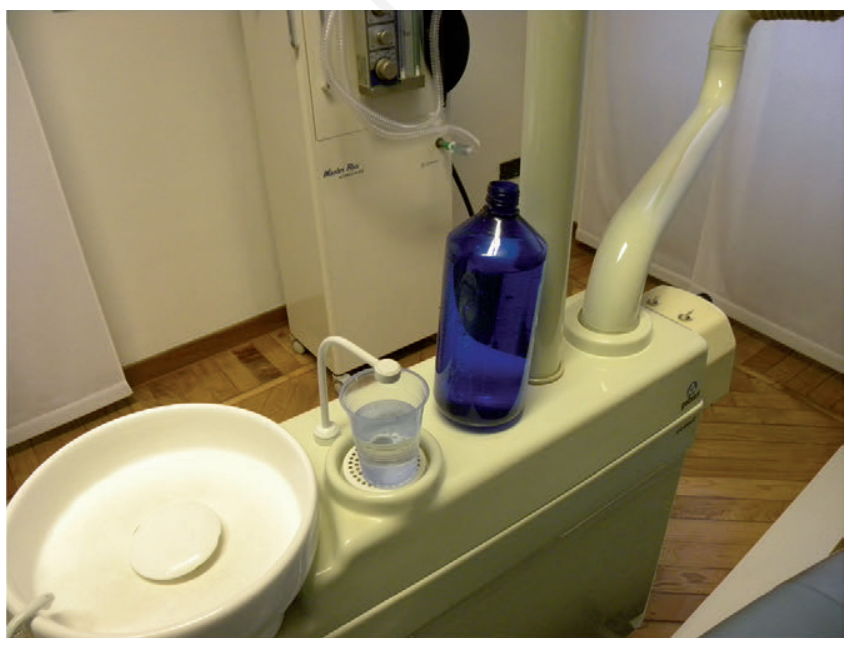

Figure 5. Picture of rinsing with hyper-ozonated water.

\section{Inoculation in bone or mucus-gengival graft}

During regenerative oral surgery, whether bone regenerative or mucogengival, it is a good rule of thumb to infiltrate at the end of surgery the graft with low ozone concentrations in order to stimulate regenerative and restorative graft processes, increase blood flow and reduce the risk of bacterial contamination of the graft itself (Figure 9). ${ }^{4}$

\section{Periodontal pocket treatment}

After scaling and root planing with hyper-ozonated water ${ }^{5}$ (Multiossigen OM3 high level) peri-radicular tissues with low concentration ozone need to be infiltrated in order to increase blood intake and stimulate the restorative processes in the offended region. The surgical wound of the periodontal pocket due to rootsanding operations must be covered with toothpaste (Ozodent) in order to reduce the risk of periodontal pocket over-infection in the first moments of clotting. This paste will also improve the seal of the gingival margin allowing for a greater permanence of ozone at high concentration insufflated inside the pocket itself (Figure 10). ${ }^{6}$

\section{Treatment of the post-extractive surgical site}

Great effect of prevention of alveolitis and post mining complications occurs with the use of ozone. After extraction, curettage of the region is carried out, an abundant wash with hyper-ozonated water. ${ }^{3}$ The surgical wound is sprinkled with ozonized paste. The surrounding tissues are infiltrated with low concentration ozone in order to promote restorative processes and blood supply. The coagulum inside the alveolus is also blown up with high concentration ozone to use its sterilizing effect (Figure 11). ${ }^{7,8}$

\section{Perimplantitis treatment}

After having exposed the implant with a surgical flap, carefully removing the infected granulation tissue surrounding the perimplant lesion, the exposed surface is scaled using hyper-ozonated water. The cleansing of the implant surface will be carried out thanks to a mechanical action given by the action of the scaler and also thanks to the use of hyper-ozonated water. Optimization of results in the treatment of perimplantitis can be achieved as soon as an intraoral device (silicone cap) can be packaged to create a

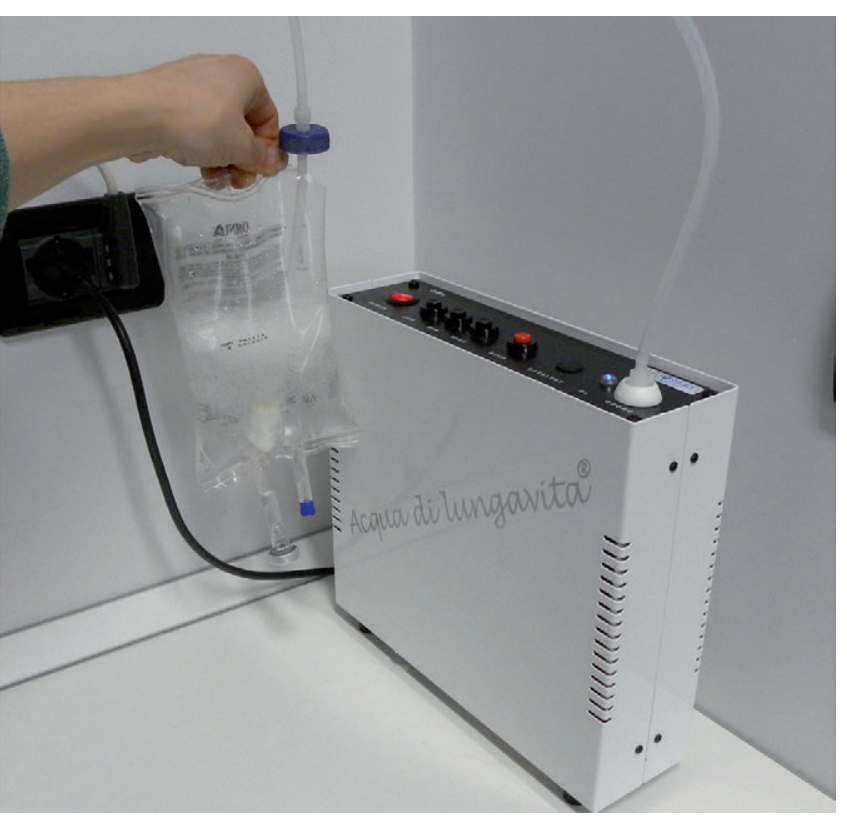

Figure 6. Picture of saline ozonization. 
watertight chamber in which the ozone oxygen mixture circulates at very high concentration for the necessary time (Figure 12). ${ }^{9}$

\section{Precautions given to the patient upon discharge}

In addition to the normal post-surgical recommendations that are generally given at discharge, the patient treated according to the protocol applied in my study are instructed not to brush in the region of the surgical wound. During oral hygiene operations involving the rest of the mouth, the ozonized paste is applied to the sutures in order to disinfect and cleanse the sutures. With this device inflammatory halos around the sutures themselves will no longer be present. The surgical wound will also be more protected against mechanical infiltration of oral fluids.

\section{Treatment and maintenance of the surgical site in the days after surgery}

The patient is invited to go to the study to carry out the followup visit the following day. The operator will thus have the possibility to control the surgical wound, clean it and, above all, infiltrate in the vicinity of the low concentration ozone-operating site in order to improve blood supply and stimulate healing. This procedure will be repeated every two days until at least the suture removal.

\section{Diagnostic ozone infiltration}

In addition to the well-known effects on the disinfection of the surgical flap, the improvement of blood supply and the promotion of healing, the infiltration of ozone at very low pressure will allow us to validate the closure of a surgical flap before proceeding with the removal of the suture (Figure 13).

\section{Removing the suture}

After checking the absence of inflammation and stability of the flap, before suturing, the patient is asked to rinse the flap with hyper-ozonated water for two minutes in order to cleanse and disinfect the sutures. ${ }^{3}$

\section{Heterologous bone hydration before grafting}

The heterologous bone material used for grafting must be hydrated before being placed in the intraoperative site. By using hyper-ozonated saline solution, it is possible to protect the graft

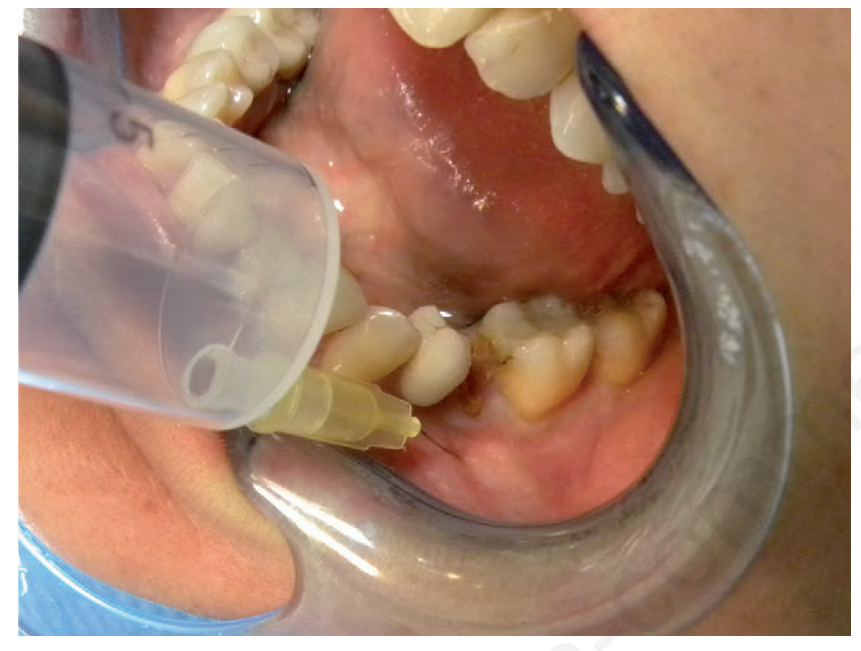

Figure 7. Picture of pre-operative gas inoculation.

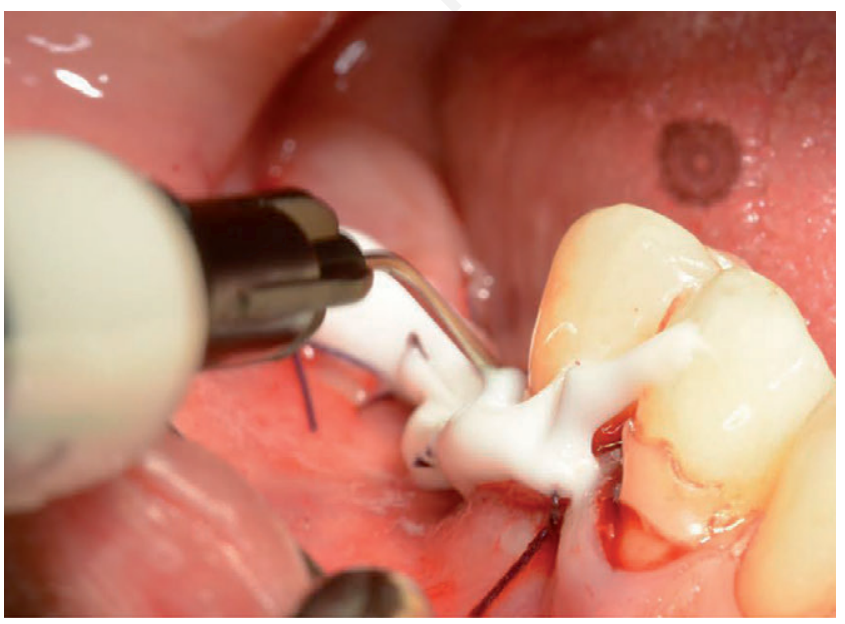

Figure 8. Picture of Ozodent toothpaste on surgical wound.

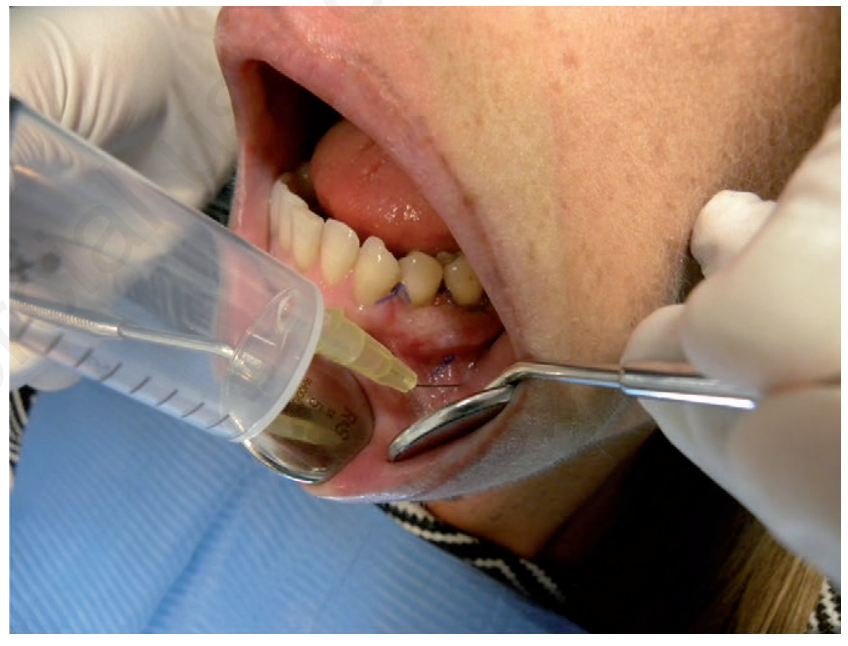

Figure 9. Picture of gas inoculation in mucous graft.

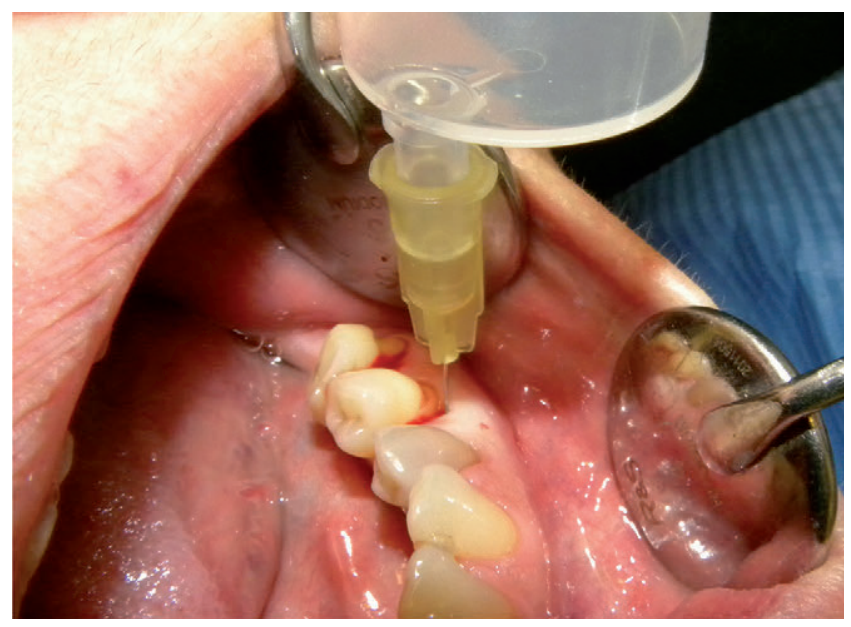

Figure 10. Picture of inoculation in periodontal pocket. 
material itself more against over-infections in the early healing stages. Reducing infectious complications in clot formation to the maximum is decisive in order to ensure correct healing (Figure 14).

\section{Conclusions}

The peculiarities of ozone gas and oxygen-ozone therapy are widely used in the field of dentistry. The stomatognathic apparatus is in fact one of the most exposed body districts to bacterial contamination. The therapeutic success of oral surgical treatments well matches the great antimicrobial effect of the gas itself. The use of ozone gas in both environmental decontamination and decontamination of the study water and dental chair itself allows increasing the hygienic and qualitative standards of dental activity. Clinical treatment with ozone to support common surgical practices offers clinical results so encouraging that it stimulates research and standardization of common protocols to scientifically highlight clinical findings. Finally, the creation of specific machinery and sanitary facilities for dentistry could also improve the use of this new device in order to optimize both antibacterial and regenerative effects.

\section{References}

1. Thomas JG, Nakaishi LA. Managing the complexity of dynamic biofilm. J Am Dent Assoc 2006;137:10-5.

2. César J, Sumita TC, Junqueira JC, et al. Antimicrobial effects of ozonated water on the sanitization of dental instruments contaminated with E. coli, S. aureus, C. albicans, or the spores of B. atrophaeus. J Infect Public Health 2012;5:269-74.

3. Sadatullah S, Mohamed N, Razak F. Qualitative analyses of the antimicrobial effect of ozonated water on supragingival plaque and salivary microbes. Ann Med Health Sci Res 2014;4:526-31.

4. Taşdemir Z, Alkan BA, Albayrak H. Effects of ozone therapy on the early healing period of deepithelialized gingival grafts: a randomized placebo-controlled clinical trial. J Periodontol 2016;87:663-71.

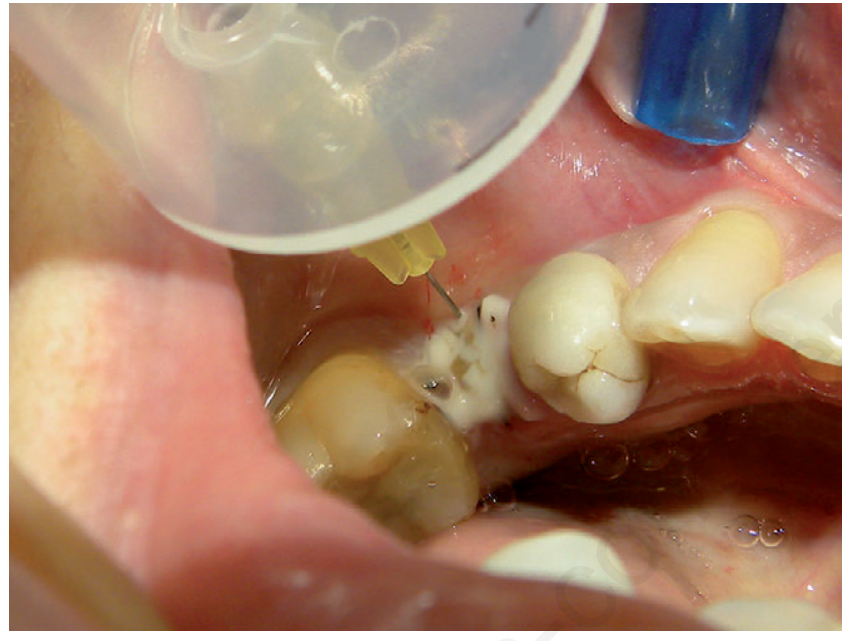

Figure 11. Picture of post-extraction alveolitis.

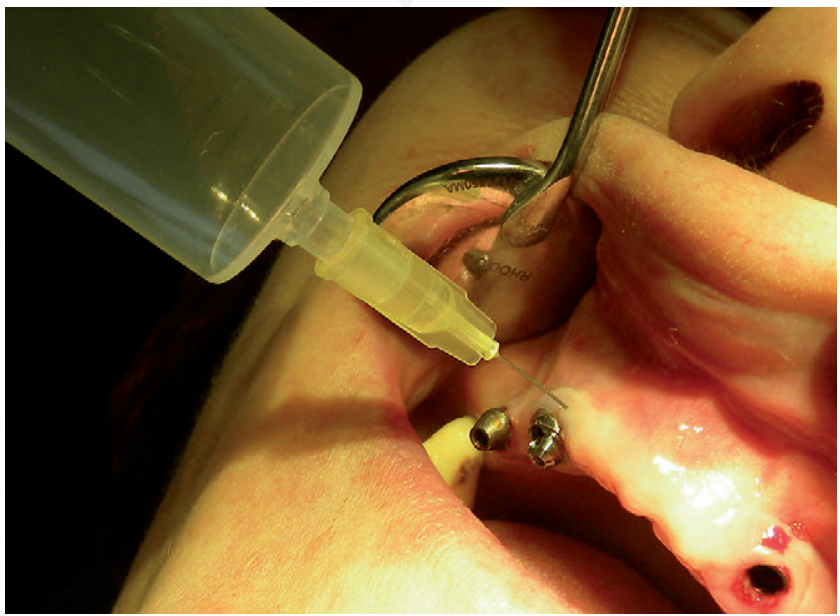

Figure 12. Treatment of perimplantitis.

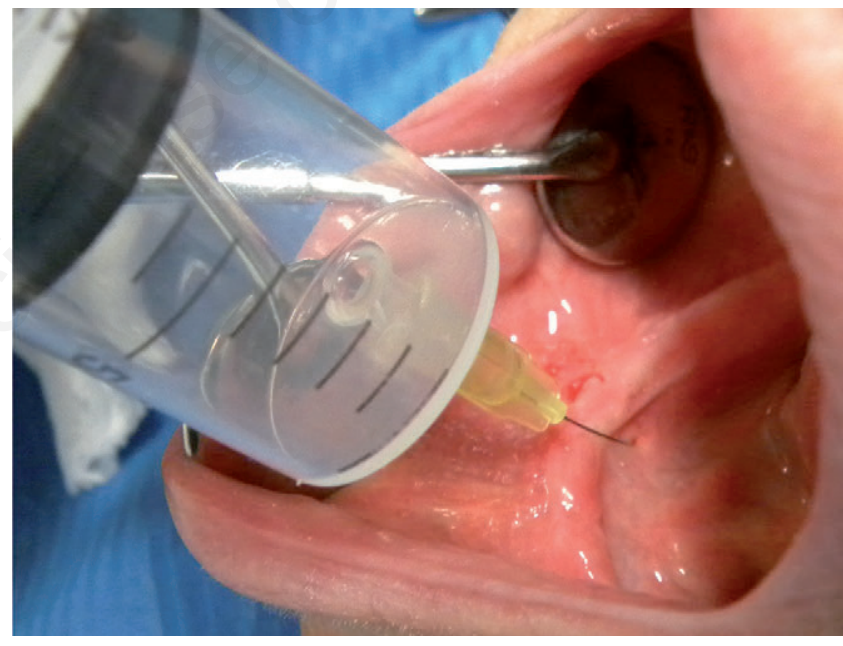

Figure 13. Picture of infiltration on closed wound.

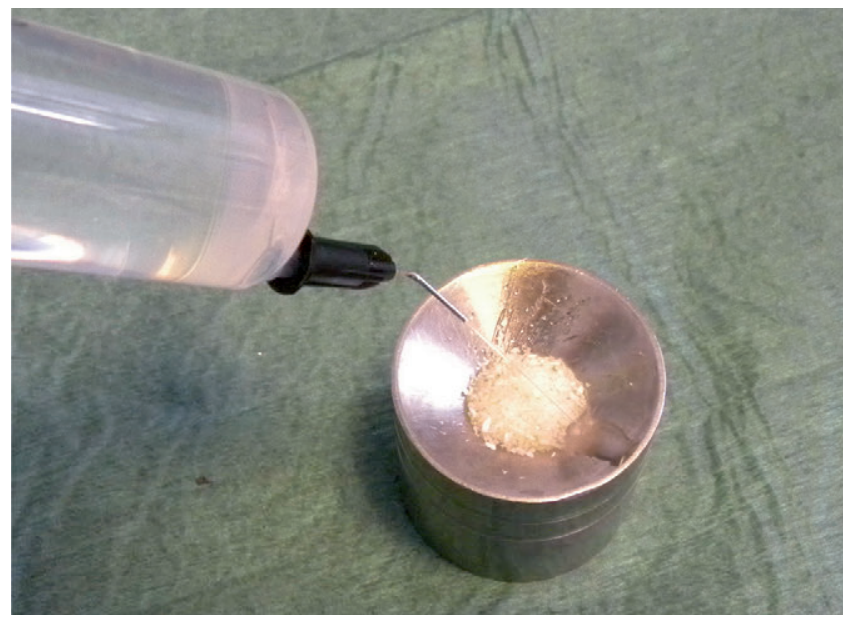

Figure 14. Heterologous bone hydration before grafting. 
5. Hayakumo S, Arakawa S, Mano Y, Izumi Y. Clinical and microbiological effects of ozone nano-bubble water irrigation as an adjunct to mechanical subgingival debridement in periodontitis patients in a randomized controlled trial. Clin Oral Investig 2013;17:379-88.

6. Al Habashneh R, Alsalman W, Khader Y. Ozone as an adjunct to conventional nonsurgical therapy in chronic periodontitis: a randomized controlled clinical trial. New Microbiol 2013;36:289-302.

7. Kazancioglu HO, Kurklu E, Ezirganli S. Effects of ozone ther- apy on pain, swelling, and trismus following third molar surgery. Int J Oral Maxillofac Surg 2014;43:644-8.

8. Ahmedi J, Ahmedi E, Sejfija O, et al. Efficiency of gaseous ozone in reducing the development of dry socket following surgical third molar extraction. Eur J Dent 2016;10:381-5.

9. Hauser-Gerspach I, Vadaszan J, Deronjic I, et al. Influence of gaseous ozone in peri-implantitis: bactericidal efficacy and cellular response. An in vitro study using titanium and zirconia. Clin Oral Investig 2012;16:1049-59. 